\title{
Adult attention-deficit hyperactivity disorder, risky behaviors, and motorcycle injuries: a case-control study
}

\section{Homayoun Sadeghi- \\ Bazargani ${ }^{1,2}$ \\ Leili Abedi $^{3}$ \\ Minoo Mahini ${ }^{4}$ \\ Shahrokh Amiri ${ }^{5}$ \\ Davoud Khorasani-Zavareh ${ }^{6}$}

'Road Traffic Injury Research Center, Tabriz University of Medical Sciences, Tabriz, Iran; ${ }^{2}$ World Health Organization Collaborating Center on Safe Community Promotion, Stockholm, Sweden; ${ }^{3}$ Department of Statistics and Epidemiology, Faculty of Health, Tabriz University of Medical Sciences, Tabriz, ${ }^{4}$ Department of Counseling, Aras International Campus, University of Tehran, Jolfa, ${ }^{5}$ Research Center of Psychiatry and Behavioral Sciences, Faculty of Medicine, Tabriz University of Medical Sciences, Tabriz, ${ }^{6}$ Social Determinants of Health Research Center, Urmia University of Medical Sciences, Urmia, Iran
Correspondence: Minoo Mahini Department of Counseling, Aras International Campus, University of Tehran, Imam Khomeini Ave., Jolfa, Iran 544656498

Tel +9 89| 440273345

Email minoomahini@yahoo.com
This article was published in the following Dove Press journal:

Neuropsychiatric Disease and Treatment

7 August 2015

Number of times this article has been viewed

Background: The aim of this study was to assess the association of motorcycle traffic injuries with motorcycle riding behavior and subtypes of attention-deficit hyperactivity disorder (ADHD) while controlling for individual correlates of motorcycle traffic injuries.

Methods: A case-control study was carried out in 298 patients with motorcycle trauma along with 151 control patients admitted to the Shohada and Imam Reza university hospitals as the two referral specialty centers in the East Azarbyjan Province of Iran in 2013. The Persian version of the Motorcycle Riding Behavior Questionnaire and the Persian version of Conner's Adult ADHD Rating Scales (the self-report short version) were used to assess riding behavior and screen for adult ADHD, respectively. The scale has four subscales, comprising subscale A (inattention), subscale B (hyperactivity, impulsivity), subscale $\mathrm{C}(\mathrm{A}+\mathrm{C})$, and subscale D (ADHD index). The statistical analysis was done using Stata version 11.

Results: All subjects were male and aged $13-79$ years. Approximately $54 \%$ of the participants were married and $13 \%$ had academic education. Approximately $18 \%$ of the motorcycle riders stated that their motorcycle riding was only for fun purposes. More than two thirds of the participants did not have a motorcycle riding license. Variables found to be significantly associated with motorcycle injuries in bivariate analysis included age, marital status, educational level, having a motorcycle riding license, using a helmet while riding, daily amount of riding, riding just for fun, riding behavior score, and ADHD scale scores. It was found in multivariate analysis that if the ADHD index (subscale D) score was used to assess the association of ADHD with motorcycle injuries, a protective role for ADHD was observed. However, the two other subscales showed a different predictive pattern for subscale A versus subscale B, with only subscale B increasing the likelihood of motorcycle traffic injuries. The score based on motorcycle rider behavior was found to be associated with motorcycle injuries. Other variables that were significant in multivariate models were the purpose of riding, educational level, economic status, and marital status.

Conclusion: ADHD and riding behavior scores affect the likelihood of motorcycle traffic injuries among motorcycle riders independent of other injury indicators, and include education, purpose of riding, and economic status.

Keywords: riding for fun, helmet, motorcycle traffic accidents, motorized two-wheelers, epidemiology, Iran

\section{Introduction}

The World Health Organization has reported that 1.27 million fatal road traffic injuries and 20-50 million non-fatal injuries occur as a result of road traffic accidents annually. ${ }^{1,2}$ Moreover, road traffic injuries are responsible for $85 \%$ of deaths and $90 \%$ of disability-adjusted life years in low-income and middle-income countries (LMICs). ${ }^{3}$ In 
most LMICs, compared with high-income countries, a much higher proportion of road users are pedestrians, bicyclists, and motorcyclists, and half of fatal road traffic injuries in LMICs occur among motorcyclists.

The psychiatric and psychological aspects of injury are an important field of study in accidentology. Psychological and psychiatric factors have been investigated both as predictors and as consequences of injury. ${ }^{3-9}$ Attention-deficit hyperactivity disorder (ADHD) is a childhood-onset psychiatric disorder. However, it is also relatively common in adults, with a prevalence reaching up to $5 \%$ in the general population. ${ }^{10}$ ADHD has been shown to be associated with suicide, addiction, increased criminality, injury, and risky behaviors. Risky behaviors in patients with ADHD are due to impaired impulse control because of problems with inhibition of prepotent responses, control of interference, and the stopping of ongoing responses after feedback on errors. ${ }^{1-14}$ Moreover, sleep problems are a common feature in ADHD patients, and have been shown to impair daytime behavior in ADHD, as well as the related emotional liability and a high variation in erroneous behavior. ${ }^{15,16}$ Studies on the role of ADHD in traffic injuries specifically focusing on the mechanism of the accident are rarely available. Although no precisely synthesized evidence of the role of ADHD in traffic injuries or the exact magnitude of such an effect exists, there are several studies emphasizing an association between ADHD and traffic injuries. ${ }^{3,8,17-19}$ The aim of this study was to assess the association of motorcycle traffic injuries with the motorcycle riding behavior and subtypes of ADHD while controlling for individual correlates of motorcycle traffic injuries.

\section{Materials and methods}

A case-control study was carried out in 298 patients with motorcycle trauma and 151 control patients admitted to the Shohada and Imam Reza university hospitals as the two specialty referral centers in East Azerbaijan Province of Iran. Tabriz is in the center of East Azerbaijan Province. The data collection was carried out in 2013. The inclusion criteria were:

- Being the rider of a motorcycle

- Being admitted to Shohada University Hospital or Imam Reza University Hospital in Tabriz, Iran

- Being injured due to a motorcycle traffic accident (for cases)

- Being admitted for a non-traumatic condition (for controls)

- Consenting to participate in the study.
The exclusion criteria included:

- No psychiatric disease except for adult ADHD

- Very severe injury preventing interview during the hospital stay

- Cognitive disorder that would render the interview unreliable.

A convenience sampling method was used to select the subjects. Samples were enrolled trying to ensure the common source population and independence of exposure from selection principles in selection of controls in case-control studies. ${ }^{20}$ The controls were age-matched with cases using a frequency matching technique. Because of the unavailability of an adequate number of controls who met the eligibility criteria, cases were enrolled in a twofold number of controls. The variables assessed in this study were:

- Demographic characteristics, including age (categorized as $<20,21-24,25-29,30-39$, and $>40$ years), marital status, and educational level (illiterate, primary school, high school)

- Human-related variables, including the injured organ, ADHD score, motorcycle riding behavior score, the reason for riding a motorcycle, the purpose of motorcycle riding (just for fun or for other purpose), helmet use (yes, no), daily amount of riding, weekly amount of riding, riding at night, and having a motorcycle rider license

- Environment-related variables, including weather conditions at the time of the accident, the shape of the road, and time of day.

The Persian version of the Motorcycle Riding Behavior Questionnaire was used to assess risky behaviors on the part of the motorcycle riders. It is a valid and reliable questionnaire with 48 items, each having a five-item Likert-scaled answer. It has been translated into Persian and validated by Motevalian et al. ${ }^{21}$ The Persian version of Conner's Adult ADHD Rating Scales (the self-report short version, PCAARS-S:SV) was validated by Sadeghi-Bazargani et al and is used to screen for adult ADHD. ${ }^{22,23}$ The scale has four subscales, ie, subscale A (inattention), subscale $\mathrm{B}$ (hyperactivity, impulsivity), subscale $\mathrm{C}(\mathrm{A}+\mathrm{C})$, and subscale D (ADHD index). The symptomatology of the scale is based on the DSM-IV (Diagnostic and Statistical Manual of Mental Disorders, Fourth Edition). However, the diagnostic criteria for ADHD in the DSM-5 (Diagnostic and Statistical Manual of Mental Disorders, 5th Edition) are similar to those in the DSM-IV. ${ }^{24}$ The items on the four subscales are summated as follows.

- Subscale A: $\mathrm{I} 1+\mathrm{I} 9+\mathrm{I} 13+\mathrm{I} 14+\mathrm{I} 19+\mathrm{I} 21+\mathrm{I} 26+$ $\mathrm{I} 29+\mathrm{I} 30$

- Subscale B: $\mathrm{I} 2+\mathrm{I} 4+\mathrm{I} 6+\mathrm{I} 8+\mathrm{I} 16+\mathrm{I} 18+\mathrm{I} 22+$ $\mathrm{I} 25+\mathrm{I} 27$ 
- Subscale C: A + B

- Subscale D: $\mathrm{I} 3+\mathrm{I} 5+\mathrm{I} 7+\mathrm{I} 10+\mathrm{I} 11+\mathrm{I} 12+\mathrm{I} 15+\mathrm{I} 17+$ $\mathrm{I} 20+\mathrm{I} 23+\mathrm{I} 24+\mathrm{I} 28$.

Descriptive analysis and bivariate tests of association were used prior to multivariate binomial regression analysis to estimate the adjusted odds ratios of ADHD and risky riding behavior scales. $P<0.05$ was considered to be statistically significant. Statistical analyses were carried out using Stata version 11 software. The study was approved by the ethics committee at Tabriz University of Medical Sciences. Written informed consent was obtained from all study participants.

\section{Results}

A total of 449 subjects, all of whom were male motorcycle riders, were included in the study. The mean age of the participants was $29.9 \pm 10.9$ years. Nearly $54 \%$ of the participants were married and 13\% had academic education. Approximately $29 \%$ of the participants were Tabriz inhabitants, $5 \%$ were from other provinces, and the remainder were from other districts in East Azerbaijan Province. The difference in baseline ratios between the case and control groups was not statistically significant.

Approximately $18 \%$ of the motorcycle riders stated that their motorcycle riding was only for fun purposes. More than two third of participants did not have a motorcycle riding license. Approximately $31 \%$ of subjects never used a helmet while riding, 29\% stated that they always used a helmet, and the remainder did not always use a helmet. The majority of motorcycles belonging to the participants (71.5\%) had an engine size of 100-125 cc. The mean riding time per week was $5.7 \pm 0.1$ days and this was not different between the groups. Approximately 413 (94\%) subjects had been riding a motorcycle for at least one year prior to the study. Only $9 \%$ of cases versus $22 \%$ of controls had an academic education $(P<0.001)$. Cases were significantly more likely to be married than single $(P<0.05)$. One hundred three $(34.5 \%)$ of cases versus 35 (24.4\%) of controls stated that they have never used helmets while riding a motorcycle $(P<0.05)$. Riding a motorcycle with an engine size smaller than $100 \mathrm{cc}$ was associated with a lower likelihood of motorcycle traffic injuries $(P<0.05)$. Those who rode a motorcycle only for fun purposes rather than for other reasons were more likely to be injured $(P<0.05)$. Multivariate statistical analysis was done according to four multivariate logistic regression models, the results of which are presented in Table 1. The first model was developed without taking into account behavioral and psychological risk indicators. The second model included ADHD scores as a whole and according to ADHD subtype. The fourth model assessed the predictive role of the behavioral scale score. Higher income and higher educational level remained statistically significant in all the four models, meaning that these two variables act as protective factors independent of psychological and behavioral scale score.

\section{Discussion}

It was found in this study that if the ADHD index (subscale D) score was used to assess the association of ADHD with motorcycle injuries in multivariate analysis, a preventive role for ADHD could be observed. However, assessment of the two other subscales showed a different predictive pattern for subscale A versus subscale B. Although studies specifically assessing road traffic injuries are limited, the available evidence from observational studies, mostly involving children ${ }^{25-34}$ and some in adults, ${ }^{18,19,35,36}$ suggests that we should expect an increased likelihood of injuries in people with ADHD. Generally, we could consider lack of concentration, impulsivity, lack of vigilance, and risk-taking to be plausible mechanisms for traffic injuries in these individuals. However, in the current study, the ADHD symptoms associated with the two ADHD subtypes showed a different pattern of association with motorcycle injuries. Although more research is needed to understand the reason behind this difference, several explanations may be put forward to account for the observed pattern, at least in part. Riding a motorcycle is generally considered to be a risky behavior in Iran, with $25 \%-30 \%$ of the total road traffic accident mortality being due to motorcycle injuries. Even having a motorcycle is expected to be more likely among subjects with ADHD, who usually have a higher tendency for risk-taking behavior. The control group in this study also comprised motorcycle riders but without injury, and this in turn may affect the association of ADHD often toward dilution of the observed association, but may also have some other effects recommended to be investigated in future research comparing two groups of control subjects who ride a motorcycle or lack motorcycles. The difference between motorcycle injuries and other types of traffic injuries, such as those sustained by pedestrians, seems to indicate a greater role of intentional risk-taking behavior rather than distraction. Therefore, those with higher subscale B ADHD scores may be at higher risk of motorcycle injury. Third, approximately $40 \%$ of road traffic mortality occurs either at the crash site or on the way to hospital, so the large proportion of individuals who die before admission to hospital could not be captured in this study; if we assume that people with ADHD are likely to have more severe injuries, then an underrepresentation of ADHD in our cases may be expected, 
Table I Multivariate binary logistic analysis of the potential determinants of motorcycle traffic injuries

\begin{tabular}{|c|c|c|c|c|}
\hline Determinants & OR & $P$-value & $95 \% \mathrm{Cl}$ & \\
\hline \multicolumn{5}{|c|}{ Model I Determinants excluding the psychiatric and risky riding behavior variables } \\
\hline Riding just for fun & 1.850219 & 0.054 & 0.98846 & 3.46327 \\
\hline Academic education & 0.377645 & 0.001 & 0.20838 & 0.68439 \\
\hline \multicolumn{5}{|l|}{ Income group } \\
\hline$<5,000,000$ IRR & Reference group & & & \\
\hline $5,000,000-10,000,000$ IRR & 0.484747 & 0.006 & 0.28887 & 0.81342 \\
\hline $10,000,000-15,000,000$ IRR & 0.393120 & 0.011 & 0.19135 & 0.80763 \\
\hline $15,000,000-20,000,000$ IRR & 0.330615 & 0.186 & 0.06400 & 1.70768 \\
\hline$>20,000,000$ IRR & 0.232304 & 0.089 & 0.04318 & 1.24959 \\
\hline Married & 1.591384 & 0.034 & 1.03642 & 2.44349 \\
\hline \multicolumn{5}{|l|}{ Daily riding amount } \\
\hline Driving $\leq$ I hour a day & Reference group & & & \\
\hline Driving $>I$ and $\leq 3$ hours a day & 0.7647993 & 0.27 & 0.47502 & 1.23134 \\
\hline Driving $>3$ hours a day & 0.487953 & 0.026 & 0.25986 & 0.91625 \\
\hline \multicolumn{5}{|c|}{ Model 2 ADHD scale as the main exposure of interest } \\
\hline PCAARS-S:SV ADHD index & 0.9219077 & 0.001 & 0.87857 & 0.967383 \\
\hline Academic education & 0.4199497 & 0.018 & 0.205294 & $0.85905 I$ \\
\hline \multicolumn{5}{|l|}{ Income group } \\
\hline$<5,000,000$ IRR & Reference group & & & \\
\hline $5,000,000-10,000,000$ IRR & 0.4557293 & 0.015 & 0.241352 & 0.860523 \\
\hline $10,000,000-15,000,000$ IRR & 0.3244573 & 0.01 & 0.13725 & $0.7670 \mid 4$ \\
\hline $15,000,000-20,000,000$ IRR & 0.2690947 & 0.118 & 0.051945 & 1.394009 \\
\hline$>20,000,000$ IRR & 0.23222 & 0.24 & 0.01964 & 2.74544 \\
\hline \multicolumn{5}{|c|}{ Model 3 Subtypes of ADHD scale as the main exposure } \\
\hline Subscale A PCAARS-S:SV & 0.7583469 & 0.001 & 0.69395 & 0.82871 \\
\hline Subscale B PCAARS-S:SV & 1.132599 & 0.003 & 1.04260 & 1.23036 \\
\hline Academic education & 0.4019177 & 0.027 & 0.17916 & 0.90162 \\
\hline \multicolumn{5}{|l|}{ Income group } \\
\hline$<5,000,000$ IRR & Reference group & & & \\
\hline $5,000,000-10,000,000$ IRR & $0.34|I 34|$ & 0.002 & 0.171282 & 0.679421 \\
\hline $10,000,000-15,000,000$ IRR & 0.2873732 & 0.01 & 0.11075 & 0.74567 \\
\hline $15,000,000-20,000,000$ IRR & 0.2479655 & 0.147 & 0.03769 & 1.63140 \\
\hline$>20,000,000$ IRR & $0 .|49573|$ & 0.165 & 0.01020 & 2.19234 \\
\hline Riding just for fun & 2.222954 & 0.04 & 1.03902 & 4.75594 \\
\hline \multicolumn{5}{|c|}{ Model 4 Motorcycle riding behavior scale as the main exposure of interest } \\
\hline Normalized riding behavior score & 1.215413 & 0.031 & 1.017894 & 1.451258 \\
\hline Academic education & 0.4003091 & 0.003 & 0.220126 & 0.727982 \\
\hline \multicolumn{5}{|l|}{ Income group } \\
\hline$<5,000,000$ IRR & Reference group & & & \\
\hline $5,000,000-10,000,000$ IRR & 0.515724 & 0.012 & 0.306797 & 0.866928 \\
\hline $10,000,000-15,000,000$ IRR & 0.3479656 & 0.004 & 0.169973 & 0.712349 \\
\hline I5,000,000-20,000,000 IRR & 0.3231123 & 0.169 & 0.064608 & 1.615926 \\
\hline$>20,000,000$ IRR & 0.3229615 & 0.24 & 0.04901 & 2.128213 \\
\hline Riding just for fun & 1.957745 & 0.036 & 1.043736 & 3.67216 \\
\hline
\end{tabular}

Abbreviations: ADHD, attention-deficit hyperactivity disorder; Cl, confidence interval; IRR, Iranian Rial; OR, odds ratio; PCAARS-S:SV, Persian version of Conner's Adult ADHD Rating Scales (the self-report short version).

leading either to underestimation of the odds ratio or even reverse associations. Fourth, the PCAARS-S:SV is not well tested in the elderly or in those under 18 years of age.

In the present study, the score based on motorcycle rider behavior was found to be associated with motorcycle injuries. Psychological explanations for risky behavior among young people have been discussed from various perspectives, including the psychodynamic approach, the cognitive approach, and the character and human motivation approach. The psychodynamic approach includes all the theories in psychology that see human functioning as being based on the interaction of drives and forces within the person and within different structures of personality. Bowlby's attachment theory and Freud's theories are included in this 
category. In the cognitive approach, there are two theories, ie, patterns of criminal thinking and Festinger's theory of cognitive dissonance. Zuckerman's sensation-seeking theory presents a personality trait characterized by seeking varied, novel, complex, and intense experiences and feelings provoking physical, social, legal, and financial risk-taking. Although all these psychological experiences have a theoretical framework, the sensation-seeking theory seems the most relevant one and appears to have a plausible link with ADHD and risk-taking motorcycle riding behaviors. ${ }^{8,37-40}$

Other predictors of motorcycle traffic injury were also investigated in the present study, and it was found that variables related to socioeconomic status, and in particular educational level, could be either risk factors or protective factors associated with motorcycle injuries. We found a significant association between being married and motorcycle injuries, which is difficult to explain. One explanation could be that married people are more likely to be riding a motorcycle during peak hour traffic or this may be related to their job or their communication or relationships are affecting their concentration while riding. Although little is known about crash patterns involving motorcycle injuries during the rush hour, it has been shown that driving during the morning rush hour triggers aggressive driving behavior and that mobile phone use while driving is more common during the rush hour. ${ }^{41,42}$ The reason for riding a motorcycle was a determinant of risk of injury in this study, eg, subjects riding a motorcycle just for fun purposes were more likely to have a motorcycle traffic injury than those riding for other or mixed reasons. Risky behaviors are expected to be more frequent among people riding a motorcycle just for fun, and safety promotion interventions may need to be different for these people. Behavior while riding a motorcycle for fun may be considered as a cause of motorcycle accidents. Young people, who ride a motorcycle just for fun, are interested in excitement gained through riding at high speeds and getting engaged in speed contests. This is also a way for them to attract the attention of bystanders. ${ }^{43}$ In Iran, perhaps due to shortage of facilities for recreation, young people consider motorcycle riding in the streets as a means of having fun. Given that young age and using motorcycle for fun are both high-risk behaviors, more intervention programs may be needed for young people. The scenario becomes complicated with addition of the psychological tendency for risk-taking in ADHD and in other psychological conditions that predispose individuals to a higher risk of motorcycle injury. Identification of psychological and behavioral risk factors for motorcycle traffic injuries could be considered as a potential step forward in safety promotion programs targeted to motorcycle riders.

\section{Conclusion}

Riding behavioral scale and ADHD subscale B scores along with age, educational level, and reason for motorcycle riding could be considered as potential determinants of motorcycle injuries. Future studies without restricting controls to being motorcycle riders are recommended.

\section{Acknowledgments}

We would like to thank all the staff at Shohada and Imam Reza university hospitals who helped with this study. We are also grateful to the Vice Chancellor of the Faculty of Health at Tabriz University of Medical Sciences for financially supporting this research.

\section{Disclosure}

The authors report no conflicts of interest in this work.

\section{References}

1. World Health Organization. Global status report on road safety 2013 Available from: http://www.who.int/violence_injury_prevention/ road_safety_status/2013/en/. Accessed June 30, 2015.

2. Peden M, Scurfield R, Sleet D, Mohan D, Hyder A, Jarawan E. World report on road traffic injury prevention. Int J Inj Contr Saf Promot. 2005; 12(2):85-91.

3. Kieling RR, Szobot CM, Matte B, et al. Mental disorders and delivery motorcycle drivers (motoboys): a dangerous association. Eur Psychiatry. 2011;26(1):23-27.

4. Grunert BK, Hargarten SW, Matloub HS, Sanger JR, Hanel DP, Yousif NJ. Predictive value of psychological screening in acute hand injuries. J Hand Surg Am. 1992;17(2):196-199.

5. Chen G, Smith GA, Deng S, Chen D, Kelleher K, Xiang H. Psychological symptoms and nonfatal unintentional injuries among Chinese adolescents: a prospective study. J Adolesc Health. 2005;37(6):460-466.

6. Chiu HJ, Chan CL, Hsu JC, et al. Nationwide retrospective cohort survey of orthopedic injuries in members of the Taiwanese population with psychiatric disorders, 2000-2005. J Orthop Sci. 2013;18(3):456-464.

7. Jaworowski $S$. Traffic accident injuries of children: the need for prospective studies of psychiatric sequelae. Isr J Psychiatry Relat Sci. 1992; 29(3):174-184.

8. Graziano PA, Reid A, Slavec J, Paneto A, McNamara JP, Geffken GR ADHD symptomatology and risky health, driving, and financial behaviors in college: the mediating role of sensation seeking and effortful control. J Atten Disord. 2015;19(3):179-190.

9. Sadeghi-Bazargani H, Maghsoudi H, Ranjbar F, Mashadi-Abdollahi H. Stress disorder and PTSD after burn injuries: a prospective study of predictors of PTSD at Sina Burn Center, Iran. Neuropsychiatr Dis Treat. 2011;7:425-429.

10. Klassen LJ, Katzman MA, Chokka P. Adult ADHD and its comorbidities, with a focus on bipolar disorder. J Affect Disord. 2010;124(1-2):1-8.

11. Rooney M, Chronis-Tuscano A, Yoon Y. Substance use in college students with ADHD. J Atten Disord. 2012;16:221-234.

12. Flory K, Molina B, Pelham W, Gnagy E, Smith B. Childhood ADHD predicts risky sexual behavior in young adulthood. J Clin Child Psychol. 2006;135:571-577.

13. Barkley R. Accidents and attention-deficit/hyperactivity disorder. Econ Neurosci. 2001;3:64-68. 
14. Groen Y, Gaastra G, Lewis-Evans B, Tucha O. Risky behavior in gambling tasks in individuals with ADHD - a systematic literature review. PLoS One. 2013;8(9):e74909.

15. Yordanova J, Albrecht B, Uebel H, et al. Independent oscillatory patterns determine performance fluctuations in children with attention deficit/ hyperactivity disorder. Brain. 2011;134:1740-1750.

16. Kirov R, Brand S. Sleep problems and their effect in ADHD. Expert Rev Neurother. 2014;14(3):287-299.

17. Aduen PA, Kofler MJ, Cox DJ, Sarver DE, Lunsford E. Motor vehicle driving in high incidence psychiatric disability: comparison of drivers with ADHD, depression, and no known psychopathology. J Psychiatr Res. 2015;64:59-66.

18. El Farouki K, Lagarde E, Orriols L, Bouvard MP, Contrand B, Galera C. The increased risk of road crashes in attention deficit hyperactivity disorder (ADHD) adult drivers: driven by distraction? Results from a responsibility case-control study. PLoS One. 2014;9(12):e115002.

19. Amiri S, Ranjbar F, Sadeghi-Bazargani H, Jodeiri EA, Navali AM, Saedi F. Association of adult attention deficit/hyperactivity disorder and traffic injuries in Tabriz - Iran. Iran J Psychiatry. 2011;6(2):61-65.

20. Wacholder S, McLaughlin JK, Silverman DT, Mandel JS. Selection of controls in case-control studies. I. Principles. Am J Epidemiol. 1992; 135(9):1019-1028.

21. Motevalian SA, Asadi-Lari M, Rahimi H, Eftekhar M. Validation of a Persian version of motorcycle rider behavior questionnaire. Ann $A d v$ Automot Med. 2011;55:91-98.

22. Sadeghi-Bazargani H, Amiri S, Hamraz S, Malek A, Abdi S, Shahrokhi H. Validity and reliability of the Persian version of Conner's Adult ADHD rating scales: observer and self-report screening versions. Journal of Clinical Research \& Governance. 2014;3(42):47.

23. Conners C, Erhardt D, Sparrow E. Conners' Adult ADHD Rating Scales: Technical Manual. Toronto, ON: Multi-Health Systems Inc; 2010.

24. American Psychiatric Association. Highlights of Changes from DSMIV-TR to DSM-5. Available from: http://www.dsm5.org/Documents/ changes $\% 20$ from $\% 20 \mathrm{dsm}$-iv-tr $\% 20$ to $\% 20 \mathrm{dsm}-5$.pdf. Accessed May 16, 2015.

25. Perera H, Fernando S, Yasawardena A, Karunaratne I. Prevalence of attention deficit hyperactivity disorder (ADHD) in children presenting with self-inserted nasal and aural foreign bodies. Int J Pediatr Otorhinolaryngol. 2009;73(10):1362-1364.

26. Ayaz AB, Ayaz M, Senturk E, Soylu N, Yuksel S, Yulaf Y. Factors related with unintentional injuries in children with newly diagnosed attention-deficit/hyperactivity disorder. Int J Inj Contr Saf Promot. October 31, 2014. [Epub ahead of print].

27. Bayar H, Coskun E, Oner V, et al. Association between penetrating eye injuries and attention deficit hyperactivity disorder in children. $\mathrm{Br}$ J Ophthalmol. February 13, 2015. [Epub ahead of print].

28. Chou IC, Lin CC, Sung FC, Kao CH. Attention-deficit-hyperactivity disorder increases risk of bone fracture: a population-based cohort study. Dev Med Child Neurol. 2014;56(11):1111-1116.
29. Herguner A, Erdur AE, Basciftci FA, Herguner S. Attention-deficit/ hyperactivity disorder symptoms in children with traumatic dental injuries. Dent Traumatol. 2015;31(2):140-143.

30. Hurtig T, Ebeling H, Jokelainen J, Koivumaa-Honkanen H, Taanila A. The association between hospital-treated injuries and ADHD symptoms in childhood and adolescence: a follow-up study in the Northern Finland Birth Cohort 1986. J Atten Disord. May 1, 2013. [Epub ahead of print].

31. Sabuncuoglu O. Traumatic dental injuries and attention-deficit/hyperactivity disorder: is there a link? Dent Traumatol. 2007;23(3):137-142.

32. Shilon Y, Pollak Y, Aran A, Shaked S, Gross-Tsur V. Accidental injuries are more common in children with attention deficit hyperactivity disorder compared with their non-affected siblings. Child Care Health Dev. 2012;38(3):366-370.

33. Silva D, Colvin L, Hagemann E, Stanley F, Bower C. Children diagnosed with attention deficit disorder and their hospitalisations: population data linkage study. Eur Child Adolesc Psychiatry. 2014; 23(11):1043-1050.

34. van den Ban E, Souverein P, Meijer W, et al. Association between ADHD drug use and injuries among children and adolescents. Eur Child Adolesc Psychiatry. 2014;23(2):95-102.

35. Hodgkins P, Montejano L, Sasane R, Huse D. Risk of injury associated with attention-deficit/hyperactivity disorder in adults enrolled in employer-sponsored health plans: a retrospective analysis. Prim Care Companion CNS Disord. 2011;13(2):pii PCC.10m01031.

36. Kaya A, Taner Y, Guclu B, et al. Trauma and adult attention deficit hyperactivity disorder. J Int Med Res. 2008;36(1):9-16.

37. Conzelmann A, Woidich E, Mucha RF, et al. Methylphenidate normalizes emotional processing in adult patients with attentiondeficit/hyperactivity disorder: preliminary findings. Brain Res. 2011; 1381:159-166.

38. Van Eck K, Markle RS, Flory K. Do conduct problems and sensation seeking moderate the association between ADHD and three types of stimulant use in a college population? Psychol Addict Behav. 2012; 26(4):939-947.

39. Boyd CJ, Young A, McCabe SE. Psychological and drug abuse symptoms associated with nonmedical use of opioid analgesics among adolescents. Subst Abus. 2014;35(3):284-289.

40. Ballon N, Brunault P, Cortese S. Sensation seeking and cocaine dependence in adults with reported childhood ADHD. J Atten Disord. 2015; 19(4):335-342.

41. Paleti R, Eluru N, Bhat CR. Examining the influence of aggressive driving behavior on driver injury severity in traffic crashes. Accid Anal Prev. 2010;42(6):1839-1854.

42. Astrain I, Bernaus J, Claverol J, Escobar A, Godoy P. [Prevalence of mobile phone use while driving vehicles]. Gac Sanit. 2003;17(1):66-69. Spanish.

43. Ghorashi Z, Kazemi M, Sayyadi A, Nasrabadi A. Experience of motorcycle accident victims: a qualitative study. J Rafsanjan Univ Med Sci. 2012; 11(2):115-127.
Neuropsychiatric Disease and Treatment

\section{Publish your work in this journal}

Neuropsychiatric Disease and Treatment is an international, peerreviewed journal of clinical therapeutics and pharmacology focusing on concise rapid reporting of clinical or pre-clinical studies on a range of neuropsychiatric and neurological disorders. This journal is indexed on PubMed Central, the 'PsycINFO' database and CAS,
Dovepress

and is the official journal of The International Neuropsychiatric Association (INA). The manuscript management system is completely online and includes a very quick and fair peer-review system, which is all easy to use. Visit http://www.dovepress.com/testimonials.php to read real quotes from published authors. 